convince the most sceptical. The microscopical sections from these two kidneys are now in the museum of the University of Edinburgh, in common with those from nearly two-thirds of my entire series.

In thirty-seven out of the forty cases there were more or less obvious indications of changes in the inner coat. Even in the three remaining cases I should not like to say positively that its thickness was perfectly normal. I accordingly consider certain changes in the tunica intima, which I am now about to describe, as practically constant features, in at least all the later and a large percentage of the earlier forms of the disease.

In the more illustrative cases the tunica intima was found to present appearances substantially identical with those described by Heubner under the name of Arteriitis obliterans, and by Thoma under that of Fibrous endarteriitis.

In the earliest examples the inner coat merely appears thicker than normal, and evinces a tendency to become fibrous. In more advanced cases the lumen is considerably narrowed, but its sides are still smooth. Viewed in transverse section, the inner coat is many times its natural breadth, and contains round cells, spindles, and fibres, with a number of wavy lines, which represent the elastic laminæ of the inner coat separated from one another by the proliferative process. Small vessels are sometimes formed for the nutriment of the thickened tunic. A drawing by Dr. Barlow in the Pathological Society's Transactions for 1877 (Plate XV., Fig. 1), representing a syphilitic artery, will convey a pretty fair idea of the state of the intima in the arteries of many interstitial kidneys. This stage is represented in Plate $V$. of my monograph above quoted.

In the most marked cases, the inner coat is greatly thickened and the lumen very much reduced, or even entirely abolished. At this stage the thickening is principally fibrous, though a few round cells and wavy lines may be visible, as in the preceding one. The character of the thickening is coarse and ragged, something like cocoanut matting. The sides of the lumen, if it still exists, are rough and splintery, and present no trace of epithelioid lining. When the artery is completely occluded, that part of the resulting solid cylinder which represents the intima is seen to consist of more or less regular concentric rings, when viewed in transverse section. These rings are dense, and are composed of closely aggregated fibres and spindles, with very few round cells.

In other instances the thickening is of a fibrous type in the earlier stages. It varies much in degree in different specimens, being as a rule most marked in the more advanced, though one of the most beautiful examples was seen in a comparatively early specimen, the surface of which was but slightly granular, and the size little diminished, though the capsule was strongly adherent, and the interstitial changes in the cortex very visible under a power of thirty diameters. In this case the thickening was cellular rather than fibrous.

(To be concluded.)

\section{CASES OF OBSCURE POISONING.}

BY J. HAWKES, M.D.

THE following cases appear to me worth recording, not so much for the interest attaching to them in a purely medical point of view, as for the additional importance they derive in their bearing on forensic medicine.

I was hastily summoned on the morning of December 18th last, about eight o'clock, to examine the bodies of two elderly persons, man and wife, who had been discovered a short time previous lying beside each other in bed, in a state of profound insensibility. The husband, who occupies a small farm on which he resides with his wife, but with no other occupant of the house, had been missed from his accustomed work earlier in the morning, and the bailiff, after seeking him in vain, mounted a ladder against his bedroom window, and having broken a pane of glass, perceived the two bodies lying together as above described. On entering the room which was of good size and airy, with an empty fireplace, I found the man and his wife lying in a natural position, comatose and breathing stertorously. The husband, a strongmade man, about sixty years of age, was pallid, his eyes closed, jaws clenched, surface of body warm, pupils moderately con- tracted, insensibility perfect. Pulse 98, full and rather strong. His wife was ghastly pale, jaws firmly clenched. Salivary foam issued from the lips, body of natural warmth, pupil of left eye contracted, right eye blind from old disease: the cheeks puffing out at each expiration, accompanied by stertorous breathing; pulse weak and irregular. No ex. planation could be afforded by anyone of the state in which they were found. I procured at once some mustard and warm water, and proceeded to administer it by teaspoonfuls placed between the teeth. The woman's mouth was, how. ever, so firmly contracted that it was necessary to thrust the spoon through a cavity where a tooth had been removed on one side. When several spoonfuls had been given without any decided effect I directed some strong coffee to be made, and continued the exhibition of this, giving it as well as the solution of mustard for a quarter of an hour. The temperature of the man's body had now become raised, and his pulse full and bounding, the state of the pupils and insensibility remaining as before. In the woman no perceptible change had occurred. I had meanwhile examined the contents of the apartment, and found a box of pills marked "dinner pills," a small 2-oz. bottle labeled "balsam of aniseed," and an ounce phial half full labeled "laudanumpoison." Having obtained the assistance of two farm labourers I caused them to move the man's body, and lift it about the room in the erect position, the lower limbs dragging helplessly on the floor. His face, however, assumed a hue so cadaverous, his eyes glazing, that I had him placed back in bed. Leaving my pupil with directions to continue the coffee in teaspoonfuls every two or three minutes, I went home and prepared an emetic of sulphate of zinc and ipecacuanha, with which, in about an hour after, I returned. The condition of the woman was unchanged-breathing stertorous, cheeks puffing out as before, the jaws firmly clenched, and pupils contracted. In the case of the man his face had lost some of its pallor; the pulse continued full, and rather strong; breathing no longer laboured or stertorous. I at once gave the emetic in teaspoonfuls, the only effect it produced on the male subject being an exaltation of temperature, return of colour in the face, and wide dilatation of the pupils. The woman vomited small quantities of mucus, besides the medicine and coffee. Slapping with a cloth steeped in cold water caused in her corrugation of the muscles of the forehead; but the same application to the man aroused him more fully, and he was able to open his eyes and move his hand and arm. These remedies were continued through the day, and I saw the patients again late in the evening, when the husband was sufficiently recovered to recognise those about him and to speak, but could tell nothing of what had passed, and knew no cause to account for his state. The woman was still unconscious. She had romited a second time; breathing stertorous at times; pupil less contracted; when addressed and shaken she opened her eyes and stared vacantly. On my visit the next morning the man was completely recovered, only feeling rather weak and exhausted; he declared himself entirely unable to account for the circumstance, and states he took only a little home-brewed ale previous to retiring to bed at nine o'clock, his wife coming to bed later. Her condition was still one of insensibility; breathing normal; pulse more regular; the colour of her face had somewhat re. turned. Ordered an egg beat up in sherry; tea at intervals, and milk. Visited the following day; found the husband dressed and downstairs; he still declares he knows nothing to explain the matter. The wife is now quite conscions and able to speak; breathing natural and healthy; colour of face normal; she denies having taken anything whatever in the form of laudanum or any other drug, and knows no reason for the insensible condition of herself and her husband. Remarks. - These persons had been known to their neighbours as quiet, inoffensive, and orderly. Three months ago they were obliged to give up a farm, and had been since employed as care-taker of the farm where they now live. The woman had an illness six years ago, during which she was said to be "very low" and suffering from over-anxiety. She has been described to me as a pecaliar, reserved woman, with something odd about her. The two lived happily together. The husband appears a very straight. forward person; he still protests he knows nothing, and feels troubled at the thought of anything having been administered to him. The woman says she only used laudanum for outward application, never internally; she also affirms her utter ignorance of any drug having been taken either by herself or her husband. Some have conjectured the zair 
were drugged in order to plunder the house, but there does not appear any foundation for this surmise. From the presence of a phial of laudanum in the bedroom, and the symptoms of each case, I have no doubt whatever that opium was the poison taken.

St. Faith's, Norwich.

\section{ADHESION OF THE PLACENTA.}

\section{BY A. CUMMINGS AIR, L.R.C.P. LoND.}

MORBID adhesion of the placenta to the uterine wall is fortunately of very unfrequent occurrence, but inasmuch as when it does happen it constitutes one of the most dangerous complications of labour, both from the great probability of its eausing profuse post-partum hæmorrhage, and also from the risk of subsequent inflammation of the womb, the accurate diagnosis of this condition is of great importance, but according to the generally received teaching of modern textbooks, it is very difficult, if not absolutely impossible. Thus Dr. Barnes in his lectures on obstetric operations says :"You may suspect morbid adhesion if there have been unusual difficulty in removing the placenta in previous labours if during the third stage the uterus contracts firmly, each contraction being accompanied by blood, and yet on fol lowing up the cord you feel the placenta still in utero; if on pulling on the cord, two fingers being pressed into the placenta at the root, you feel the placenta and uterus descend in one mass, a sense of dragging pain being elicited; if during a pain the uterine tumour do not present a globular form, but be more prominent than usual at the place of placental attachment." Dr. Playfair says :- "The cause of adhesion is often obscure, but it most probably results from a morbid state of the decidua, which is produced by antecedent disease of the uterine mucous membrane then the adhesion is apt to recur in subsequent pregnancies. .... . There are no very reliable signs to indicate morbid adhesion of the placenta previous to the introduction of the hand. And Dr. Churchill: "The diagnosis is in almost all cases impossible until the extraction is attempted; a strong suspicion will be excited, however, by the occur rence of uterine contraction, without extrusion of the afterbirth. The previous history of the patient may in some degree confirm these suspicions; if she have suffered much pain in some fixed part of the uterus during pregnancy, it may have resulted from inflammatory action. Whenever we see a patient suffering thus we should always ascertain by the stethoscope whether it is in the situation of the afterbirth, so that we may be prepared for the consequences at the time of labour.

I have met with several cases of morbidly adherent placenta, during the last fourteen years, and am inclined to believe that the diagnostic problem may be solved with almost absolute certainty; although from my experience being limited to so short a time I would desire to write with all becoming modesty.

The diagnosis is, I think, to be founded upon two symptoms, one of which is mentioned by Dr. Churchill, the other by Dr. Barnes-viz., that at some period of pregnancy, generally between the third and fifth month, a fixed pain, generally of a dull aching character, is felt over some part of the uterus; and this is converted into a severe dragging pain when the patient attempts to turn over to lie on the side opposite to the placental site; so much so that patients with an adherent placenta will never (as far as my experience goes) voluntarily lie on that side. This pain, I believe, to be of the same nature as that mentioned by Dr. Barnes, as being experienced when the cord is drawn upon ; and is due to the dragging on the cord by the child when from gravitation it sinks through the liquor amnii.

Theoretically, it may be objected to this explanation that usually the cord is sufficiently long to prevent any such dragging; but I think it will generally be found that when the cord is long, it is twisted around the neck or limbs of the child, and produces the same effect as a short cord would.

No history of this dragging pain on the patient's turning to the side opposite to the placental insertion will be obtained, when the retention of the after-birth is merely due either to the inertia of a wearied uterus, or from irregular contraction; if there is hæmorrhage in either of these cases, one would be justified in trying the effect of cold, compression, \&c.. before introducing the hand, but in cases of true placental adhesion, trying these and similar means leads to dangerous loss of precious time.

Kennington-park-road.

\section{A : ithirror}

\section{HOSPITAL PRACTICE,}

\section{BRITISH AND FOREIGN.}

Nulla antem est alia pro certo noscendi v1a, nisi quamplurimas et morborum t dissectionum historias, tum aliorum tum proprias collectas habere, e inter se comparare.-Moresanr De Sed. et Caus. MKorb., lib, iv, Procemium

\section{ROYAL LONDON OPHTHALMIC HOSPITAL.}

CASES OF OPTIC NEURITIS AND NEURO-RETINITIS.

(Under the care of Mr. HULKE.)

ROUGHLY-SORTED cases of optic neuritis, with which it is convenient to place congestive swelling of the optic papilla, fall into two classes, one in which the neuritis is associated with some intracranial disorder which stands in a causal relation to it, the other in which no such intracranial disorder is present: neuritis optica descendens and neuritis optica non-descendens. The wider interest felt in cases of the first class has attracted greater attention to these. They are of very frequent occurrence, and good examples often present themselves in the out-patient room. The implication of both the optic nerves is often not simultaneous in its onset, but one nerve is attacked before the other, so that the two nerves not unfrequently exhibit different phases of inflammation, and sometimes one nerve only is in. volved.

CASE 1.- - aged eight, a weakly child, with double scrotal rupture, was sent up to the hospital from the east coast, absolutely blind. The right papilla optica was swollen and cloudy, and the veins were very turgid. The morbid appearances in the left eye were similar but somewhat less strongly marked. The pupils, notwithstanding that perception of light was absent, were not dilated, but small, and they contracted with convergence of the eyes. Six months previously the child had had very severe headache with retching. After a fortnight the right eye was thought to be blind, and soon after this the sight of the left failed. At the end of three months both were quite blind. When taken to the hospital he was free from headache, had not latterly retched, and he looked in good health.

CASE 2.- - aged six years, was taken to the hospital by his mother, who for some time had thought his sight imperfect. Tried with Jäger's scales, he read No. 19 with the right eye, and with the left eye No. 2. The right optic papilla was swollen, and its veins very turgid. He was a delicate-looking child. In his second year he was noticed to frequently brush his forehead with his hand, as if he felt some uneasiness there, and about that time a knot (gumma?) appeared in the left biceps humeri, which disappeared later, About the same time he occasionally squinted, and he then began to have fits. These at first occurred at in. tervals of two or three weeks ; they had continued up to the time of the visit, and had latterly become more frequent. From the description given of them the fits were epileptiform. His manner had become cold, wilful, and excitable.

CASE 3.- - a a a seden, when first seen at the hospital was quite blind. Both optic papillæ were swollen and opaque, and the retinal veins were very turgid and tortuous; within the opaque area they were lost to view wherever they dipped away slightly from the surface. The child was thought healthy until five months previously, when she fell ill. She was drowsy and listless, would not play, but lay about all day, and she often vomited. Soon the mother thought her sight failed. Three months after she was brought to the hospital the swelling and opacity of the optic nerves were replaced by whiteness, unnatural distinctness of lamina cribrosa and smallness of vessels - in short, by the signs of atrophy. The child's general condition was better. 